ALPHA N² 28 Julio 2009 (233-244)

ISSN 0716-4254

http://alpha.ulagos.cl

\title{
COMPLEJIDAD, ESPACIO, TIEMPO E INTERPRETACIÓN. (Notas para una hermenéutica del territorio) ${ }^{1}$
}

Complexity, space, time and interpretation. (Notes for an hermeneutics of the territory)

Nelson Vergara*

\section{INTRODUCCIÓN}

Las notas que presentamos no constituyen propiamente un trabajo interpretativo, hermenéutico, sino un conjunto de reflexiones sobre cuestiones que nos parecen relevantes a la hora de desarrollar una hermenéutica en sentido estricto. Esas cuestiones, espacio, tiempo e interpretación, son parte de un sistema complejo que debe revelar la imposibilidad de mantener una reflexión sobre realidades en el sentido moderno del término y que deben ser leídas, por tanto, en las direcciones que hoy día abre la noción y concepto de complejidad.

En lo esencial, postulamos una aproximación a la comprensión de lo que llamamos territorio. Al respecto, queremos cruzar tres coordenadas que refieren hoy día a problemas cruciales, tanto para efectos de intelección de las realidades territoriales como para, eventualmente, asumir responsabilidades de convivencia que se derivan de ese conocimiento y que - a la hora de comprometernos con nuestros entornos - creemos que son epistemológica, metafísica y políticamente relevantes.

La primera es una coordenada relativa al espacio y al tiempo. Muchos pensadores consideran que vivimos la era del espacio, así como el siglo XIX vivió la del tiempo. Y no es que las preocupaciones por el espacio hayan dejado a las espaldas nuestras preocupaciones por el tiempo. Más bien se refieren a que el tiempo mismo se presenta, propiamente, como una dimensión del espacio, de modo que ahora ya no es posible referirse a aquél con independencia de éste (M. Foucault, 1999). El espacio ha sido siempre algo muy relevante, aunque hoy día lo sea a un nivel superlativo. Sin embargo, una muy significativa corriente de opinión destaca, también, que nuestra época es

\footnotetext{
${ }^{1}$ Este trabajo es producto del Proyecto de Investigación № 002007, “Cartografía de prácticas cotidianas urbanas: apropiación cultural de espacios públicos de la ciudad de Osorno”, financiado por la Dirección de Investigación de la Universidad de Los Lagos para los años 2007-2008.
} 


\section{Nelson Vergara}

la era del tiempo, de la temporalidad, aunque no de la temporalidad, así sin más, sino de aquélla que nos sitúa en la historia y que conocemos con el nombre de historicidad. Según esta opinión, que parece oponerse a la Foucault, no hay asunto humano que pueda ser entendido fuera del tiempo. Más aún, que, en cierto modo, el ser es tiempo (C. Castoriadis, 2002-2005) lo que nos permite conjeturar que acaso también el espacio, en cuanto forma de ser de lo real, es tiempo. Lo que no quiere decir que el espacio sea el tiempo, o que el espacio se reduzca a tiempo. Ni la identidad ni la reducción parecen caminos adecuados de intelección, según nos lo presenta hoy día E. Morin (2003).

Una segunda coordenada es la de la interpretación, sobre todo aquella que afirma su necesidad, precisamente, en épocas como la nuestra en que grandes cambios van posesionándose de la vida sociocultural, dándole al mundo esa fisonomía que nos hemos acostumbrado a relacionar con las crisis históricas. Hay algo en estas crisis que pone en juego el o los sentidos de las cosas y no resisten sólo explicaciones. Requieren, también, comprender las direcciones de los cambios y sus efectos mediatos e inmediatos, así como evaluar la consistencia y el estado de las aspiraciones y sueños personales y colectivos. A este encuentro acude, nos parece, la hermenéutica (H. G. Gadamer, 1993) como esclarecimiento o restauración de sentidos (P. Ricoeur, 2002; G. Vattimo, 1996) en momentos cuando la verdad parece ocultarse tras un velo de evidencias pragmáticas que privilegian la utilidad y la inmediatez.

La tercera coordenada es aquella que, cada vez más, se ha venido apropiando de nuestros modos de abordar lo real en cualesquiera de sus manifestaciones. Se trata de esa condición que se ha instalado con el nombre de complejidad y que, al parecer, atraviesa todo lo real, sea efectivo o imaginario, conceptual o virtual. Según esto, y si obviamos por lo pronto la aparente banalidad de la expresión "nada es simple" entonces debemos asumir la responsabilidad de justificarla. Más aún, la complejidad de lo real debe revelar que lo complejo efectivo exija la consideración de las complejidades teóricas e imaginarias y viceversa, en una inter-retroactividad que E. Morin (2003) y otros (K. Popper, 1992; F. Varela, 2000) van a defender ad limite y contra toda evidencia en contrario. Sobre todo en contrario de esas evidencias que, desde Descartes y en toda la época Moderna, se atribuyeron a la sana razón o al buen sentido y que, luego, fue trasladado acrítica y arbitrariamente a la racionalidad científica. Así, el positivismo. Entonces, "nada es simple”, es cierto, aunque en rigor no sea plenamente verdadero. Y esta convicción ha venido marcando los derroteros de nuestro tiempo, en una confrontación con la modernidad que, para muchos, no ha concluido (J. Habermas, 2004; M. Augé, 1996). Quede dicho con toda su ambigüedad que es, desde ya, decidora y significativa. Pero, veámoslo en los contextos que hemos señalado. 
I. En primer lugar, conectamos — como se hace habitualmente- el territorio con su base más evidente: el espacio. Según esto, el territorio es una de las formas como este espacio se nos da, si bien de un modo determinado. Otras formas son, por ejemplo, el lugar, el paisaje, el sitio, el no lugar, etc. En lo fundamental, como espacio, el territorio es un entorno. Pero, no un entorno abstracto, aparte e independiente, sino siempre un entorno de alguien, una colectividad, o una persona en cuanto pertenece a una colectividad. Entonces el territorio es un espacio de la vida plural, colectiva, social o cultural, y no un mero marco físico en que se localizan las cosas. Es decir, no un espacio ahí, simplemente, aparte, objetivo y suelto, por sí, sino un espacio vivido. Por tanto, al decir que el territorio es un espacio de la vida plural, se dice que no posee autonomía de quienes se encuentran en él, en tanto que su estar allí, es un hallarse siendo ahí, un encontrarse siendo constructores del ahí, mancomunados con él según condiciones que el propio espacio exige, sugiere o suscita. Esto es, habitándolo. En este sentido se ha dicho que el espacio es una construcción social, cualquiera que sea la figura que adopte. Y el territorio es una de esas formas. Pero, el territorio es, a la vez, un espacio vivido. En esta dimensión, el espacio territorial es parte de lo Otro, sin lo cual alguien concebido como Mismo, no lo sería. Y más aún, lo Otro tampoco sería Otro: de aquí que Mismo y Otro sean categorías que siempre se espacializan indicando distancias, por ejemplo, un cerca o un lejos, o un lejísimo que marca la máxima otredad territorial posible. Quizás por esto se ha afirmado que el territorio es esencialmente espacio apropiado (Giménez, 2004) hecho propio, y significado como pertenencia: lo Mío y lo de los Demás, desde Mí o desde los Otros, reconocidos por mí, o por nosotros - entre quienes pueden colindar los territorios - hasta el extraño, el extranjero que viene de muy lejos, y a quien no reconozco porque nada sé de él, es decir aquéllos que provienen de otro territorio, que como hemos indicado representa mi máxima alteración u otredad espacial. El territorio es, entonces, siempre mi espacio o el espacio de los otros, semejantes o distintos de mí o de nosotros, en quienes puedo reconocerme como lo que esencialmente soy, así como los otros se reconocen en el suyo.

Pero sabemos, también, que el asunto es más complejo, porque el Nosotros nunca alude a la totalidad de lo que nos rodea y que ese "nosotros" suele ocultar oposiciones y, a veces, muy hondas entre los que supuestamente estamos en lo Mismo. También es plural la vida en este sentido y esa pluralidad suele cobrar formas confrontacionales de grandes alcances. De este modo, el espacio-territorio es vivido como plural en un sentido efectivo y no abstracto o imaginario.

Por esto, también, el espacio territorial es vivido como plural en un sentido simbólico: significa distintos momentos y circunstancias de la vida y 


\section{Nelson Vergara}

es signo inequívoco de valores espirituales diversos, desde lo aparentemente más banal e insignificante (territorio supuesto indistintamente como de todos y de nadie, tal como solemos referirnos a lo que hoy día llamamos el espacio fiscal, donde el término mismo "fisco" es, desde ya, banal e insignificante, aunque no siempre lo fuera), hasta lo más profundamente inhabitual y, paradójicamente, más significativo: el espacio ceremonial que suele asimilarse a lo sagrado, pero que no es incompatible con rituales profanos. Es el territorio plenamente identificatorio de esto o de lo otro, de lo común o de lo excepcional. Pero siempre propio, es decir, asegurado como inherente e indesligable de uno mismo, como no sea por la fuerza (como la usurpación, el desalojo, la enajenación legal o expropiación, o el abandono, obligado o elegido, el robo, etc.) que, paradójicamente también, acoge en esta condición un poderoso refuerzo en su simbolismo. Sobre todo cuando está conectado a actos de violencia. El sentimiento del nómada es un ejemplo muy claro en la actualidad. También lo es el de quien ha perdido el territorio por efectos del exilio. Emigrantes o inmigrantes y exiliados llevan consigo parte de lo que han sido, así como también dejan ahí parte de lo que es suyo. Del mismo modo aquellos que sienten que su territorio les ha sido usurpado y que confían en poder recuperarlo alguna vez, como es el caso de algunos pueblos indígenas en la actualidad.

$\mathrm{Y}$ este es el punto más claro, nos parece, en que el tiempo hace su emergencia en el centro de la vitalización del espacio-territorio, historizándolo. Por esto, el espacio no es, en realidad, separable del tiempo: vivimos aquí o allá, pero, vivimos ahora o antes o después, en otro sitio y en otro momento, etc. Nos situamos y situamos a los otros en este cruce, que se nos aparece como encrucijada, encrucijada efectiva o simbólica, como dilema espacio-temporal. Por esto, también, el territorio se carga de tabúes, rituales, ceremonias, fiestas, sobre todo fiestas (M. Delgado, 1999-2007). Utopías y heterotopías (M. Foucault, 1999) son signos inequívocos de referencias espacio-temporales y no solamente espaciales a lo que estamos entendiendo por territorio. $\mathrm{Y}$ en todos los planos. También en aquéllos planos poéticos, donde los cuerpos, como lugares o paisajes, son recorridos como propios o extraños por quien busca o sigue sus huellas en el tiempo. Y así como sueño e imaginación se corresponden, también ruinas y memoria colectiva se copertenecen. Pero veamos con más detalle uno de estos casos. Quizás si una de las figuras más impresionantes de esta dimensión espacio-temporal del territorio sea la Utopía. Grandiosa o banal, redentora o intrascendente, la utopía simboliza aquel lugar que no es propiamente un lugar, sino la aspiración a que algo reemplace, aunque sea por negación, a lo ya existente: no es la propuesta de algún lugar efectivo ahora, sino la postulación de algo desde el cual lo existente puede ser cuestionado y negado, y obligado a 
hacerse ver en sus defectos y limitaciones (M. Foucault, 1999; P. Ricoeur, 2002). Todas las ideologías, grandes o pequeñas, suponen o exigen, y, en esta medida, señalan hacia ella en cuanto símbolo de la proyección y trascendencia de los espacios territoriales: metáforas espacio-temporales que van dibujando los contornos de la experiencia vivida, sea como presente, como pasado o como futuro. Por esto, la utopía no solamente es un futuro: está también en los orígenes al que se sueña volver, que se añora y rememora, que se hace un lugar en nuestras emociones y memorias, y que nos llama a un rescate del tiempo. Y está, también, en el presente, en las luchas por la recuperación del pasado que permita abrirse camino hacia adelante y que tiene la misión de dar cumplimiento a un destino: metáfora, también, de un vacío que señala a un virtual tiempo recobrado, aunque sea sólo imaginativamente.

Sin embargo, no podemos obviar otros referentes de la expresión "espacio" que parece apoderarse de nuestros discursos; expresiones que guardan una relación parcial con territorios, quizás metafóricas, pero que indican bastante bien la condición situacional de nuestras experiencias. No sería inoficioso referir a ellas aunque sea brevemente. Me refiero a lo que se significa con los términos "espacio cultural", "espacio comunicativo", "espacio social”, "espacio civil” etc. Ni qué decir de las nociones conocidas como "espacio público", "espacio privado" o, como lo ha dicho M. Foucault (1999), "espacios otros". Son verdaderamente espacios territoriales que también pueden ser vistos como símbolos en los que se retratan experiencias que se institucionalizan, ritualizándose. $\mathrm{Y}$ en estos contextos, lugares, no lugares, paisajes, son también fuente de experiencias simbolizadas, metaforizadas como en la expresión "lugares de la memoria”, "espacios del temor”, "espirales de violencia”, "redes del narcotráfico”, "carreteras de la información”, etc., expresiones todas que de algún modo más o menos explícito, hacen alusión a sus condiciones de ocurrencia y concreción material en sitios o terrenos específicos. Esto sin obviar que los términos red, espiral, carretera, etc., son símbolos de la espacialidad en nuestro tiempo.

Pero aún hay otra dimensión en que el territorio, en cuanto espacio y tiempo vividos, encuentra su posibilidad de realización: es su dimensión poiética, productiva, práctica, una de las cuales, fundamental, es la práctica discursiva, la práctica en que el territorio se dice, esto es, se inscribe en el lenguaje, se abre camino a través y mediante el decir. Empírica o simbólicamente, el espacio se temporaliza en el lenguaje y, así, va a ser medido en la historia. Paradójicamente, el lenguaje hace que el espacio no solamente esté en el tiempo, sino que en rigor sea tiempo, y acaso no sea sino y solamente tiempo. Puede ser. La vida cotidiana ha dicho H. Giannini (1990), es lo que pasa todos los días. Se entiende, que es también lo que nos pasa. Y el territorio es siempre algo que nos pasa de múltiples maneras. Quién sabe si 


\section{Nelson Vergara}

una de esas maneras sea precisamente la metáfora, la forma poética, la creación, en el sentido que C. Castoriadis (2002) da a este término, aunque creo que también en el sentido religioso de la expresión. Quiero decir que así como estimamos que hay un lugar para cada cosa, lo que nos remite al pensamiento griego, también nos pertenece la convicción de que cada cosa reclama un tiempo, según lo indica el pensar hebreo.

II. Pero así como el espacio no puede ser comprendido separado del tiempo y éste no parece ser posible al margen del lenguaje, la metáfora (el símbolo) es, a juicio de P. Ricoeur (2002), co-extensiva con la interpretación.

Aseguremos de entrada que "interpretación" es un término cuyo referente, ha sufrido, como dice Sábato (1979) de la novela, todas las violaciones. Por esto diseñaremos un camino, una ruta posible que nos lleve a una noción, a un concepto que nos permita ver lo que queremos ver. Y esta ruta requiere, como lo afirmara K. Popper (1983-1992) que la interpretación sea entendida desde ya como objetivación de instancias subjetivas, conjeturas, equivalentes hoy a lo que solemos llamar "lectura": esto es, indagación de una hipotética realidad de algo, en nuestro caso, del territorio, nuestro espaciotiempo apropiado. Tal indagación no es espontánea ni puramente constativa. Exige que se ejerza sobre ciertas realidades, simbólicas o simbolizables y que ese símbolo (nuestra metáfora) no sea inmediatamente comprendido o comprensible. Admitimos, entonces, con H. G. Gadamer (1993), que así como lo interpretable es una realidad de múltiples profundidades, la interpretación es una indagación paso a paso hacia esas profundidades, las que requieren ser esclarecidas, sacadas a luz, iluminadas o puestas en evidencia, cuestión que se logra, siempre aproximadamente, en la labor hermenéutica.

¿De qué modos específicos se puede realizar esta indagación que parece presentarse como una "arqueología”? Paul Ricoeur (2002), entre otros hermenéuticos contemporáneos, nos señala algunas direcciones viables y confiables tales como la del desocultamiento o desenmascaramiento, descubrimiento de lo oculto o rescate de lo olvidado en el tiempo, todas son configuradoras de sistemas interpretativos igualmente operantes, porque en ellas se actualizan procesos en que se desbrozan sentidos plurales que se ocultan en sistemas simbólicos. Así, el rescate de lo olvidado, de lo sumido en el tiempo, según la feliz expresión de Humberto Giannini (1990), o restauración de sentidos de acuerdo con Paul Ricoeur (2002), son las modalidades en que se manifiesta, ocurre y concurre nuestra intelección al encuentro de esos sentidos que yacen ahí, en la materialidad lingüística del territorio o, quizás, en la memoria, quizás en la imaginación, y que se apodera de las subjetividades para hacer posible el reencuentro con experiencias soterradas, ocultas a los sentidos inmediatos con que enfrentamos las cosas ya habituales. Por esto, la hermenéutica es siempre "arqueología”, teoría y práctica de búsquedas de lo 
profundo de algo. Como “América profunda”, por ejemplo, en el decir de Kusch —o "Chiloé profundo", del que quiere hablarnos Sergio Mansillaterritorios de lo ilimitado, lugares sin definición, paisajes de lo oculto, caminos de bosque, como gustaba decir M. Heidegger (1967). Todas ellas son expresiones de grandes símbolos que requieren ser dilucidados también, profundamente. Así, creemos que no hay modo de llegar a lo hondo, a lo que "arqueológicamente" oculta un territorio como no sea hermenéuticamente, interpretativamente, ya en un sentido literal o en un sentido indirecto, efectivo o imaginariamente, pues son las formas en que los territorios se presentan aludiendo a lo latente que ocultan. Pero, reiteremos ¿Dónde indagar? ¿Dónde yace realmente lo latente, lo profundo del territorio que se manifiesta en la metáfora o el símbolo? ¿Qué es lo que se somete a la tarea "arqueológica”? Dicho de otro modo: significaciones, sentidos ocultos, sinsentidos, contrasentidos ¿Qué tipo de objetos son? ¿Dónde se encuentran realmente y cómo se conectan con la interpretación? Hay aquí, nos parece, dos cuestiones necesarias de dilucidar previamente y que constituyen cuestiones de doctrina: primero, que metáfora e interpretación son co-extensivas e interdependientes, como decía P. Ricoeur (2002), es decir que ninguna de ellas es autónoma y subordinante de la otra, sino que, al decir de Sartre (1965) y Ortega (1972), se dan al mismo tiempo como relativas una a la otra, siendo, según Ortega, coexistentes. Y a tal punto lo son que nos parece que la metáfora es, desde ya, interpretación así como la interpretación, que no está justificada sino frente a aquélla, acaso no sea sino una forma metafórica también, sin que esto las confunda o reduzca una a la otra.

Sin embargo, para que acontezca nos parece que tiene que darse una clara condición: que ambas tengan un lugar de procedencia común. A nuestro juicio, la procedencia común instala la segunda cuestión doctrinaria: que lo anterior es posible porque metáfora e interpretación pertenecen al ámbito del decir, del manifestar a través o en virtud de la palabra. De esta manera podemos establecer que el lugar en que se opera hermenéuticamente cuando se trata del territorio (o, en verdad, de cualquier otro objeto o realidad) es el ámbito abierto por el lenguaje en acción, el campo de las significaciones. Interpretar el territorio es entonces indagar en lo profundo de esas significaciones inscritas en el decir y posibilitadas por el decir. Pero, entonces, la pregunta se traslada a otra: ¿Dónde están depositadas estas significaciones que se expresan o manifiestan metafóricamente mediante el decir? Uno estaría tentado a señalar que están en el entorno, en una parte del entorno: ahí, por ejemplo, en esos paisajes, en esas figuras, en esos relatos. En principio, nos parece que esto no es erróneo porque, en efecto, ahí están ese sentido o esos sentidos latentes. Pero, ¿Qué indagamos cuando enfrentamos esos sentidos latentes? No por cierto el paisaje en sí, o las figuras en sí, o los relatos en sí. 


\section{Nelson Vergara}

Pero sí los paisajes, figuras o relatos en tanto manifestación simbólica de algo relativo a una conciencia.

¿A qué conciencia nos referimos aquí? No es, claro, la conciencia en tanto que se opone a un inconsciente, o a un mero no saber o ignorar, como cuando decimos que no tenemos conciencia de algo, queriendo decir que no nos hemos percatado. Más bien, aludimos al hecho común de señalar una instancia abierta a toda referencia y donde esa referencia puede hacerse visible, accesible a un darse cuenta implícito en distintas formas, tales como las sensaciones, percepciones, representaciones o pensamientos. Todo esto, sin embargo, con una salvedad: no se trata de introspección. La hermenéutica, como interpretación, no es una indagación en y hacia la intimidad de alguien que puede ser uno mismo - como una suerte de indagatoria en la autoreferencia - sino de aquello que H. Giannini (1990) ha llamado la "experiencia común”, y que I. Mukarovski (1972) denomina “conciencia colectiva”, lugar social y cultural en que el lenguaje ha decantado y dejado marcas de su pasar como tiempo y significación. Indagamos, entonces, en esas huellas a través del lenguaje que nos las señalan como paisajes, como figuras, como relatos; especialmente como relatos, porque la conciencia colectiva se manifiesta en y por los relatos que nos narran esa experiencia que queremos o necesitamos "leer". De aquí su irrestricta conexión con la emoción y la memoria colectiva. De este modo, paisajes, figuras, relatos no son sino sistemas de significación en que decanta la experiencia común y, por esto, su aprehensión no es, no puede ser, inmediata y directa, sino que exige una labor, a veces ardua, de desentrañamiento, de búsqueda conjetural de sentidos que son conjeturas también, interpretaciones de otro grado. Y así, de esta manera que parece ir en espiral, paisajes, figuras o relatos, son formas en que una comunidad se representa (en el sentido dramático, teatral del término, es decir, como interacción de actores y entornos) el territorio como su espacio, el espacio que se ha apropiado, reconociendo en él distintas significaciones, desde lo más banal a lo más sagrado, pero donde lo banal y lo sagrado son polos de lo propio, de una pertenencia obligada, enraizada y construida estrato por estrato, como una formación geológica. Hay en este sentido metáforas de lo banal e insignificante, de lo superficial, tan reales como aquellas metáforas de lo inhabitual y sagrado, de lo profundo. De lo más cotidiano, recogemos ejemplos en las expresiones, "andar bajoneado", "aterrizarse”, "vivir en las nubes", "encumbrado", "quebrarse”, así como también "sumergirse en los abismos”, "abrazar la luz”, etc. En ellas se inscriben, reconocen, perviven y comunican lo que llamamos experiencias de vida, cotidianidad, conciencia colectiva en tanto saber en que se halla una comunidad, en el doble sentido de encontrarse ahí y de sentirse bien. De aquí la enorme importancia de las narrativas en que decanta la vida cotidiana. Y, quizás, no haya otros factores 
más relevantes para decir las correlaciones entre símbolo (o metáfora) e interpretación que estas realidades en que se manifiesta nuestra tercera categoría en juego: la complejidad del espacio territorial.

III. Complejo, complexus, tejido, trama: entramados de asuntos, de discursos, de palabras y cosas, de experiencias, de modos de hacer o deshacer cosas con palabras o sin ellas; hacerse un lugar en la trama de asuntos de facto o de lenguajes, universos o pluriversos de significaciones y referencias, es parte de las tantas maneras como E. Morin (2003) nos ha transmitido su idea de lo complejo. Y nos ha dicho lo que siempre hace falta decir y reiterar: que, quizás, no hay otra experiencia más especialmente compleja que la propia vida cotidiana, experiencia en que dialogan los diversos componentes de la experiencia común que, más que nadie, los novelistas nos han dado a conocer.

Formalizando lo ya referido, sostengamos con E. Morin (2003) que la complejidad parece, a primera vista, "un fenómeno cuantitativo: una cantidad extrema de interacciones e interferencias entre un número muy grande de unidades” (59). Pero la complejidad no contempla sólo cantidades - dice Morin - "contempla también incertidumbres, indeterminaciones, fenómenos aleatorios” (60). Y lo que, a su juicio, es decisivo: afirma que la complejidad está relacionada siempre con el azar. Múltiples combinaciones que afectan, entonces, a lo real efectivo, biológico, psíquico, social, tanto como al pensamiento se despliegan constituyendo tanto el orden como el desorden, el azar como la necesidad, lo manifiesto como lo latente, instituyendo como real también las incertidumbres y el riesgo. Ninguna realidad escapa a esta condición, por lo que se exige, desde el inicio, una actitud que haga posible comprender tanto la inclusión como la exclusión, lo objetivo como lo subjetivo, la acción como la retroacción, en un fondo de incertezas que se pueden conjurar pero nunca eliminar. Y no es que lo simple no exista en absoluto. Sólo que no tiene realidad autónoma como creyó la modernidad. Así afirma Morin que en la investigación hay que ir "de la complejidad hacia aún más complejidad. Lo simple, repitámoslo, no es más que un momento, un aspecto entre muchas complejidades (microfísica, biológica, psíquica, social)” (61-62). Pero ¿Cómo reconocemos la complejidad de esa realidad que estamos llamando territorio? Aventuramos aquí una conjetura más: la complejidad del territorio nos parece que se encuentra en esa condición humana que denominamos territorialidad. Veamos cómo es esto, de acuerdo a lo que llevamos establecido. Toda realidad lo es siempre de algo para alguien, hemos dicho. Hay aquí una doble intencionalidad que es necesario respetar: el territorio aparece como el espacio apropiado por y para aquellos que lo habitan, efectiva, imaginaria o virtualmente. $\mathrm{Y}$ es para habitarlo que se apropian de él, que lo hacen suyo materialmente al ocuparlo o abandonarlo, ya que la ausencia suele medirse, también, en huellas materiales, así como lo 


\section{Nelson Vergara}

hacen suyo también simbólicamente - al decirlo- nombrándolo o rememorándolo de múltiples maneras. Por lo tanto, el territorio se despliega en las palabras que lo hacen, que lo construyen socialmente, como en las efectividades que materializan esas palabras en tanto el símbolos del acontecer de cada cultura en el alma de sus habitantes. Territorios producetivos, territorios del poder o del dominio, territorios de la concertación o del conflicto, del encuentro o desencuentro, territorios de la fiesta y de lo sagrado, territorios habituales y ancestrales, territorios conquistados, territorios subyugados, territorios agotados, territorios utópicos, territorios de la exclusión y de la discriminación, territorios prohibidos, etc. Largas cadenas de redes entrecruzadas de circunstancias e interpretaciones; todas complejas y no de razones - como quería Descartes - sino de experiencias integrales, experiencias de mundos vividos. Todo esto habla bastante bien de la coexistencia entre hombres y espacios-tiempos, mediados por la comprensión en esa figura de vida que es la interpretación. La vida se interpreta a sí misma, decía Ortega. Pero se interpreta de las múltiples formas como se va dando en la sociedad y en la cultura y nunca de modo homogéneo. La unidad de la vida es una unidad relativa de diferencias, una estructura dinámica.

Pero entonces, reafirmamos, el territorio es inherente a la condición humana de un modo específico. A esta forma específica llamamos territorialidad, ambiente y horizonte espacio-temporal de toda experiencia colectiva que se despliega dentro de límites que cada cultura se da en su devenir. Pero esta condición territorial, como tal, tiene, a su vez, su propia complejidad, a la que aludiremos aquí una vez más, someramente.

La territorialidad es una categoría efectiva y discursiva; un modo de ser de alguien que para ser lo que aspira a ser tiene que desplegarse en acciones concretas de realización efectiva y de palabra, ocupando espacios, entorno, y espacios subjetivos que siente como suyos y a la vez reconociéndose en ellos. Así, la territorialidad es inherente a la construcción de la vida que se va dando en su despliegue y, a la vez, va guiando todo ensanchamiento o estrechamiento espacial, toda mantención o ruptura de los horizontes de lo habitable. La territorialidad no es, entonces, un mero encontrarse en un espacio propio pero externo, como una conciencia refleja, testigo, sino una suerte de voluntad territorial que se va desplegando desde adentro hacia afuera, apropiándose de lo externo, subjetivándolo, trasladando o transfiriendo intimidad al entorno. En este sentido, la territorialidad es una condición real en virtud de la cual la subjetividad y la objetividad se dan al mismo tiempo, co-determinándose una a la otra, sin relación alguna de dependencia.

Para efectos de una hermenéutica, sin embargo, debemos hacer notar que la territorialidad es una realidad cuyo concepto denota dos dimensiones claramente diferenciables. Por un lado, es una realidad que hace evidente una 
condición genérica de alguien a quien le es consustancial pertenecer a un territorio, es decir, que le es esencial y no secundaria. Territorialidad designa entonces una interconexión necesaria de alguien con su entorno, la que se da en términos de inevitabilidad. En ella, el territorio habla a y por quien lo habita y en este diálogo se co-determinan de múltiples formas. Pero, por otro lado, la territorialidad designa una condición sociocultural específica. Y en este plano ya no denota una dimensión metafísica, genérica, sino claramente una dimensión histórico-social, circunstancial, contingente, un aquí y ahora que se despliega como ambiente o como atmósfera que, en cuanto situación sociocultural, adviene, deviene, acontece, pasa, permanece o cambia, pero no se pierde aunque pueda asumir formas contrapuestas y dispares. Así, considerando ambas dimensiones, la territorialidad es una condición invariable, un destino, pero que como tal, paradójicamente, se despliega y se desarrolla; llega a ser, deja de ser; se proyecta, se desgasta, vuelve a construirse, se rescata, etc., en la interacción constante entre el hombre y sus entornos. Desde la primera dimensión, el hombre es un ser territorial. Desde la segunda es un ser de este territorio y lo es a la manera suscitada por esa conexión, efectiva o imaginaria, pero temporal y cultural.

En síntesis, como teoría y práctica interpretativa, la hermenéutica del territorio tiene que contemplar ambas dimensiones, situación en la que dialogan significativamente. Por esto, la moderna tendencia a la simplicidad, a la reducción, chocará siempre con la complejidad de los fenómenos que no se dejan atrapar como datos elementales, concatenados causal y linealmente, sino como instancias cuya complejidad es siempre sistémica y que, dando lugar al azar, ha establecido a la encrucijada como uno de sus símbolos más eminentes y monumentales: materialmente, el cruce de caminos en el que los horizontes se confunden; espiritualmente, la duda, la incertidumbre que obliga a decisiones arriesgadas.

\author{
Universidad de los Lagos* \\ Departamento de Humanidades y Arte \\ Casilla 933, Osorno (Chile) \\ nvergara@ulagos.cl
}

\title{
BIBLIOGRAFÍA
}

AUGÉ, Marc. El tiempo en ruinas. Barcelona: Gedisa, 2003.

------- El sentido de los otros. Barcelona: Paidós Ibérica, 1996.

BOISIER, Sergio. El desarrollo en su lugar. El territorio en la sociedad del conocimiento. Santiago: Universidad Católica de Chile. Instituto de Geografía. Serie GEO Libros, 2003.

------- Modernidad y territorio. Santiago: Cuadernos del ILPES, 1996. 
Nelson Vergara

CASTORIADIS, Cornelius. Los dominios del hombre. Las encrucijadas del laberinto II. Barcelona: Gedisa, 2005.

------- Figuras de lo pensable. Las encrucijadas del laberinto VI. México: F. C. E., 2002.

DELGADO, Manuel. Sociedades movedizas. Pasos hacia una antropología de las calles. Barcelona: Anagrama, 2007.

------- El animal político. Hacia una antropología de los espacios urbanos. Barcelona: Anagrama, 1999.

FOUCAULT, Michel. Estética, Etica y Hermenéutica. Obras esenciales III. Barcelona: Paidós Ibérica, 1999.

GADAMER, Hans Georg. Arte y verdad de la palabra. Barcelona: Paidós Ibérica, 1998.

------- El problema de la conciencia histórica. Madrid: Tecnos, 1993.

GIANNINI, Humberto. La "reflexión cotidiana". Hacia una arqueología de la experiencia. Santiago: Universitaria, 1990.

GIMENEZ, Gilberto. “Territorio, paisaje y apego socio-cultural”, en VVAA Primer Foro Regiones culturales Culturas-regionales. México: Dirección de Vinculación Regional (2004):29-50.

HABERMAS, Jürgen. "Modernidad: un proyecto incompleto", en N. Casullo (Compilador). El debate modernidad-Postmodernidad. Buenos Aires: Retórica, 2a edición (2004):53-63.

HEIDEGGER, Martin. Sendas perdidas, Buenos Aires: Losada, 1967.

MORIN, Edgar. Introducción al pensamiento complejo. Barcelona: Gedisa, 2003.

MUKAROVSKI, I. et al.El círculo de Praga. Valparaíso: Universitarias, 1972.

ORTEGA Y GASSET, José. “Origen y epílogo de la filosofía”, en Revista de Occidente. Madrid: Col. El Arquero, 1972.

POPPER, Karl. Conocimiento objetivo. Un enfoque evolucionista. Madrid: Tecnos, 1992.

------- Conjeturas y refutaciones. El desarrollo del conocimiento científico. Barcelona: Paidós Ibérica, 1983.

RICOEUR, Paul. Freud: una interpretación de la cultura. México: Siglo XXI, 2002.

------- Ideología y Utopía. Barcelona: Gedisa, 2001.

SABATO, Ernesto. El escritor y sus fantasmas. Barcelona: Seix-Barral, 1979.

SARTRE, Jean Paul. El hombre y las cosas. Buenos Aires: Losada, 1965.

VARELA, Francisco. El fenómeno de la vida. Santiago: Dolmen, 2000.

VATTIMO, Gianni. La sociedad transparente. Barcelona: Paidós Ibérica, 1996. 